\title{
Factors that predict fertility desires for people living with HIV infection at a support and treatment centre in Kabale, Uganda
}

\author{
Othman Kakaire', Michael O Osinde², Dan K Kaye ${ }^{3^{*}}$
}

\begin{abstract}
Background: Studies from different contexts worldwide indicate that HIV positive patients manifest high-risk sexual behavior characterized by fertility intentions, multiple sexual partners, non-use of contraceptives and non-disclosure of HIV status to their sex partners. The objective was to analyze fertility desires among persons living with HIV at a treatment centre in Kabale Hospital, Southwestern Uganda.

Methods: From January to August 2009, we interviewed 400 HIV positive patients seeking care using an interviewer-administered questionnaire. We assessed socio-demographic variables, reproductive history, sexuality and fertility desires. At bivariate and multivariate analysis, characteristics of participants who reported or did not report desire to have a child in the near future were compared.
\end{abstract}

Results: Of the 400 respondents, (25.3\%) were male, $47.3 \%$ were aged $25-34$ years, over $85 \%$ were currently married or had ever been married, and the $62 \%$ had primary level of education or less. Over $17 \%$ had produced a child since the HIV diagnosis was made, and $28.6 \%$ reported that they would like to have a child in the near future. Age of the respondent, being single (versus being ever-married) and whether any of the respondents' children had died were inversely associated with fertility intentions.

Conclusion: Factors inversely associated with fertility intentions were age of the respondent, marital status and whether any of the respondents' children had died. Use of antiretroviral therapy was not associated with fertility intentions.

\section{Introduction}

The majority of new human immunodeficiency virus (HIV) infections that occur in children worldwide occur among children born to HIV positive mothers, who acquire the HIV infection from their mothers [1]. Through HIV treatment and support centres, HIVinfected persons and their partners are provided with the required information about the HIV prevention and treatment strategies available [2]. Despite counseling, studies from different contexts worldwide in both developed countries [3-7] and developing countries [8,9] in the era of wide access to antiretroviral drugs [10-13] indicate that many HIV positive individuals continue to exhibit high risk sexual behavior characterized by fertility

\footnotetext{
* Correspondence: dankkaye@yahoo.com

${ }^{3}$ Department of Obstetrics and Gynecology, Makerere University Medical

School, P.O. Box 7072, Kampala, Uganda

Full list of author information is available at the end of the article
}

intentions. Studies from Uganda indicate that 3-20\% of married or cohabitating couples are HIV sero-discordant [14-16]. Within a given socio-cultural context, measuring fertility intentions among HIV-positive individuals (who were advised against having children) is a good indicator of the reproductive choices made by HIV positive individuals. The objective was to analyze fertility intentions among persons living with HIV/AIDS at a treatment and counseling centre in Kabale Hospital, Southwestern Uganda, and specifically, analyze whether being on antiretroviral therapy was associated with fertility intentions.

\section{Methods}

\section{Study setting}

Kabale District is a rural highland district in southwestern Uganda, about $560 \mathrm{~km}$ from the capital city, Kampala. The 2002 national census estimated the population of Kabale District at about 471,800, with an 
annual population growth rate of $3 \%$. This district is densely populated-with an area of 1,827 square kilometers, the population density in the district in 2009 is estimated at 318 people per $\mathrm{km}^{2}$. Kabale Hospital is a public regional referral hospital funded by the Uganda Ministry of Health and general care in the hospital is free.

\section{Study design}

The study design was a cross-sectional study conducted at Kabale hospital HIV treatment and counseling centre, from January to August 2009. The study inclusion criteria were having attended for at least three months, availability of HIV sero-status results, HIV positive diagnosis and willingness to consent for participation in the study. During the eight-month study period, 400 HIV positive individuals were recruited into the study

\section{Data collection procedure}

Participants were screened and recruited by research assistants who were health workers attached to the HIV treatment, care and support centre. Using an intervieweradministered questionnaire and through records review of information in the client database, data was collected on socio-demographic variables such as age, education level, marital status, number of years in marriage, employment status, and social habits (drinking alcohol or smoking). Reproductive history: parity and number of living children(number of biological children of the respondent who were alive), sexuality (number of sexual partners, change of sexual partners, frequency of sexual intercourse and condom use) were also assessed. For fertility intention, individuals' subjective feelings regarding future conception (whether the respondent wanted to have a child in the next two years) was assessed.

\section{Data analysis}

Data was analyzed using the STATA software (Release 9) to provide frequencies and percentages for categorical variables and means and standard deviations for numerical variables. At bivariate analysis, characteristics of the participants who reported fertility intentions were compared with those who did not, using Pearson's chi-square test for categorical data and Student $t$-test for numerical data. To adjust for confounding, collinearity and interaction and thereby analyze factors that were independently associated with fertility intention, multivariate logistic-regression analysis was conducted. During the stepwise modeling for regression analyses, all variables of clinical importance or with p-value 0.2 and less on bivariate analysis were considered for inclusion. Intention to have a child in the near future (fertility intention) was entered as intends $=1$, does not intend $=0$. Ever treatment for sexually transmitted infection since the HIV diagnosis was entered as Ever treated $=1$, Never treated $=0$. Consistent contraceptive use was entered as present $=1$, absent $=0$. Parity, number of living children and age of spouse, age of sexual debut and age at marriage were entered as numerical variables. Other categorical variables were entered as present or yes $=1$, and absent or $N o=0$. Participant age was evaluated as a numerical variable and as 5-year age categories. The model goodness-of-fit of the final logistic regression models was assessed by Pearson's chi-square test.

\section{Ethical considerations}

Ethical approval was obtained from Kabale Regional Hospital. Counseling about sexuality, condom use, dual protection and fertility was provided to all the participants, and all eligible participants were provided with antiretroviral therapy.

\section{Results}

Of the 400 respondents (Table 1), 101 (25.3\%) were male, $47.3 \%$ were in the age category $25-34$ years, over $85 \%$ were currently married or had ever been married, and $62 \%$ had primary level of education or less. The mean age of sexual debut, age at marriage and age when participants had their first child was 18.3 years, 20.5 years and 21.8 years respectively. Only 191 (53.1\%) described their intimate relationships as stable.

Table 2 shows the reproductive history of the respondents stratified by gender. Of the 400 respondents, 63 (17.6\%) had produced a child since the HIV diagnosis was made, and 108 (28.6\%) reported that they intended to have a child in the near future (within next two years). Fifty four respondents (13.4\%) were unaware that if they were HIV positive, they could pass on the virus to the unborn baby. Only 214 (53.1\%) reported that they were aware that their regular sexual partner/partners knew their HIV sero-status, despite 330 respondents (82.5\%) already taking antiretroviral drugs. Of the 197 (49.3\%) who were aware of the partners' HIV sero-status, 170 (86.7\%) knew the partners were HIV positive. More than $10 \%$ had had sexual intercourse with more than one sexual partner in the previous 6 months.

In table 3 , having produced a child since the HIV diagnosis, being single (versus being married, separated or divorced), the number of living children, whether the respondent perceived the relationship as stable and having had sex in the previous six months were significantly associated with fertility intention (though respondents reported less likelihood of desiring to have children in the next two years) (p-value less than 0.05). On the other hand, the number of sexual partners in the previous six moths was significantly associated with fertility intention (those with more sexual partners were more likely to have fertility intention (p-value less than 0.05)). Being on ARVs was not significantly associated with fertility intentions. In table 4 , being on antiretroviral 


\begin{tabular}{lc}
$\begin{array}{l}\text { Table } \mathbf{1} \text { Socio-demographic characteristics of the study } \\
\text { participants }\end{array}$ & $\begin{array}{c}\text { Number (Percentage) or Mean } \\
\text { ( } \text { Standard deviation) }\end{array}$ \\
\hline Characteristic & $101(25.3)$ \\
\hline Sex & $299(74.7)$ \\
Males & $55(13.8)$ \\
Females & $106(26.5)$ \\
\hline Age category & $79(19.8)$ \\
Less than 24 years & $53(13.3)$ \\
$25-29$ years & $37(9.3)$ \\
$30-34$ years & $51(12.8)$ \\
$35-39$ years & $20(5.1)$ \\
$40-44$ years & \\
$45-49$ years & $140(35.3)$ \\
50 years or more & $205(51.2)$ \\
\hline Religion & $32(8.0)$ \\
Catholic & $23(5.0)$ \\
Protestant & \\
Moslem & \\
Others &
\end{tabular}

Do you have stable sexual relationship?

\begin{tabular}{lc} 
Yes & $191(53.1)$ \\
No & $159(46.9)$ \\
\hline Marital status & $59(14.8)$ \\
Single & $196(49.0)$ \\
Married & $111(27.8)$ \\
Widow/widowed & $34(8.4)$ \\
Divorced or separated & \\
\hline Level of education & $58(14.8)$ \\
No formal education & $188(47.1)$ \\
Primary & $124(31.1)$ \\
Secondary & $30(7.9)$ \\
Tertiary or university &
\end{tabular}

\begin{tabular}{lc}
\hline Drink alcohol & \\
Yes & $93(23.4)$ \\
No & $307(76.5)$ \\
\hline
\end{tabular}

Have any of your children

died?

\begin{tabular}{lc} 
Yes & $158(39.5)$ \\
No & $242(60.5)$ \\
\hline Number of living children & $3.0 \pm 1.4$ \\
\hline Mean age of sexual debut & $18.3 \pm 2.9$ \\
\hline $\begin{array}{l}\text { Mean age at first marriage if } \\
\text { married }\end{array}$ & $20.5 \pm 3.8$ \\
\hline $\begin{array}{l}\text { Mean age when participants } \\
\text { had first child }\end{array}$ & $21.8 \pm 3.9$ \\
\hline
\end{tabular}

therapy was not significantly associated with fertility intentions. The factors independently associated with desiring a child in the near future among HIV positive persons were age of the respondent, marital status and when any of the respondents' children had died. Young
Table 2 Reproductive and sexual history of the study participants stratified by gender

\begin{tabular}{lcc}
\hline Characteristic & Males; & Females; \\
Number & Number \\
(Percentage) & (Percentage) \\
\hline
\end{tabular}

\begin{tabular}{lll}
\hline *Are you currently using contraceptives & & \\
Yes & $61(60.4)$ & $149(40.5)$ \\
No & $29(39.6)$ & $141(49.8)$ \\
\hline *Do you have stable sexual relationship? & & \\
Yes & $62(31.7)$ & $129(43.1)$ \\
No & $35(69.3)$ & $133(56.9)$ \\
\hline *Have you had sex in the last 3 months? & & \\
Yes & $74(38.2)$ & $163(54.5)$ \\
No & $26(41.8)$ & $133(45.5)$ \\
\hline *On average, how often did you have sex & & \\
in the last 3 months? & $15(14.9)$ & $32(10.7)$ \\
At least 3 times per week & $38(37.6)$ & $82(27.4)$ \\
Around once a week & $22(21.8)$ & $47(15.7)$ \\
About once a month & $16(15.8)$ & $115(38.5)$ \\
Less frequently than once a month &
\end{tabular}

*How many sexual partners have you had

in the last 6 months?

\begin{tabular}{lcc} 
None & $22(21.8)$ & $113(37.8)$ \\
One & $59(58.4)$ & $158(52.8)$ \\
Two & $10(10.5)$ & $10(3.3)$ \\
Three & $5(5.0)$ & $4(1.3)$ \\
More than 3 & $2(2.0)$ & $7(2.3)$ \\
\hline${ }^{*}$ Does your regular partner know your HIV & & \\
status? & $68(67.3)$ & $146(48.8)$ \\
Yes & $19(32.7)$ & $57(51.2)$ \\
No & $93(92.1)$ & $235(78.6)$ \\
\hline Are you currently is on ARVs? & $8(7.9)$ & $64(21.4)$ \\
Yes & & \\
No & $57(90.5)$ & $112(84.2)$ \\
\hline${ }^{*} / S$ your partner HIV positive? & $6(9.5)$ & $21(15.8)$ \\
Yes & & \\
No & & \\
\hline *Have you changed regular sexual partners & & \\
since HIV diagnosis? & $62(61.4)$ & $210(64.9)$ \\
Yes &
\end{tabular}

Key- ${ }^{*}$ Non response was partly due to some respondents were not sexually active or did not have sexual partners

age, those who were single (as compared to the evermarried) and respondents whose children had died were significantly less likely to have fertility intentions.

\section{Discussion}

Since access to antiretroviral therapy has improved quality of life and survival for HIV infected people, many will contemplate child bearing. Identification of contextual determinants of decision to have children among HIV positive couples is useful for designing of policies 
Table 3 Bivariate analysis of factors associated with fertility intentions among HIV positive individuals attending the HIV care and support centre

\begin{tabular}{|c|c|c|}
\hline Characteristic & $\begin{array}{l}\text { Odds ratio and } \\
\text { confidence limits }\end{array}$ & p-value \\
\hline \multicolumn{3}{|l|}{ Sex } \\
\hline Male versus Female (reference group) & $1.80(1.00,3.24)$ & 0.050 \\
\hline Age of respondent & $0.56(0.46,0.67)$ & $<0.001$ \\
\hline Age at sexual debut & $0.98(0.90,1.06)$ & 0.558 \\
\hline Religion & $0.92(0.70,1.22)$ & 0.574 \\
\hline \multicolumn{3}{|l|}{ Marital status } \\
\hline Single versus married, divorced or separated & $0.54(0.41,0.72)$ & $<0.001$ \\
\hline Occupation & $0.92(0.79,1.07)$ & 0.292 \\
\hline $\begin{array}{l}\text { Drinking habits } \\
\text { Drinks versus does not drink }\end{array}$ & $0.65(0.39,1.09)$ & 0.107 \\
\hline Number of living children & $0.83(0.70,0.97)$ & 0.027 \\
\hline $\begin{array}{l}\text { Whether any of the respondents' children died } \\
\text { Yes versus No }\end{array}$ & $0.97(0.61,1.54)$ & 0.891 \\
\hline $\begin{array}{l}\text { Whether respondent is on ARVs } \\
\text { Yes versus No }\end{array}$ & $1.52(0.87,2.66)$ & 0.142 \\
\hline $\begin{array}{l}\text { Whether respondent had sex in previous } 6 \text { months } \\
\text { Yes versus No }\end{array}$ & $0.38(0.62,0.92)$ & $<0.001$ \\
\hline Number of sexual partners in the previous 6 months & $1.31(1.01,1.71)$ & 0.041 \\
\hline $\begin{array}{l}\text { Has the respondent disclosed HIV status to sexual partner/partners? } \\
\text { Yes versus No }\end{array}$ & $0.81(0.45,1.4)$ & 0.478 \\
\hline $\begin{array}{l}\text { Are any of respondent's sexual partners HIV positive? } \\
\text { Yes versus No }\end{array}$ & $1.00(0.76,1.34)$ & 0.953 \\
\hline $\begin{array}{l}\text { Has participant changed sexual partners in previous } 3 \text { months? } \\
\text { Yes versus No }\end{array}$ & $0.69(0.42,1.12)$ & 0.146 \\
\hline $\begin{array}{l}\text { Is the respondent currently using contraceptives? } \\
\text { Yes versus No }\end{array}$ & $0.75(0.48,1.20)$ & 0.226 \\
\hline $\begin{array}{l}\text { Is the respondent using dual protection? } \\
\text { Yes versus No }\end{array}$ & $0.96(0.75,1.20)$ & 0.753 \\
\hline $\begin{array}{l}\text { Since the HIV diagnosis, has the respondent produced a child? } \\
\text { Yes versus No }\end{array}$ & $0.40(0.23,0.69)$ & 0.001 \\
\hline $\begin{array}{l}\text { When does the respondent you use condoms? } \\
\text { With regular partners versus with casual partners }\end{array}$ & $0.89(0.52,1.53)$ & 0.673 \\
\hline
\end{tabular}

Table 4 Factors among the HIV positive participants that independently predict fertility intentions

\begin{tabular}{lll}
\hline Covariate & $\begin{array}{l}\text { Odds ratio and } \\
\text { confidence limits }\end{array}$ & p-value \\
\hline Age of respondent & $0.55(0.43,0.71)$ & $<0.001$ \\
\hline Sex of respondent & $1.10(0.51,2.25)$ & 0.861 \\
\hline $\begin{array}{l}\text { Marital status } \\
\text { Single versus ever married (married, separated or widowed) }\end{array}$ & $0.61(0.41,0.90)$ & 0.012 \\
\hline Number of living children & $0.99(0.79,1.24)$ & 0.946 \\
\hline $\begin{array}{l}\text { Are any of the respondents' children dead? } \\
\text { Yes versus No }\end{array}$ & $0.48(0.26,0.88)$ & 0.018 \\
\hline $\begin{array}{l}\text { Is respondent is currently on ARVs? } \\
\text { Yes versus No }\end{array}$ & $1.13(0.57,2.27)$ & 0.724 \\
\hline $\begin{array}{l}\text { Has the respondent had sex in previous } 6 \text { months? } \\
\text { Yes versus No }\end{array}$ & $0.48(0.21,1.07)$ & 0.075 \\
\hline $\begin{array}{l}\text { Average number of sexual partners } \\
\text { Any number versus None }\end{array}$ & $1.07(0.80,1.44)$ & 0.635 \\
\hline $\begin{array}{l}\text { Has respondent changed partners since HIV diagnosis? } \\
\text { Yes versus No }\end{array}$ & $0.84(0.45,1.54)$ & 0.571 \\
\hline
\end{tabular}


and establishing intervention priorities in reproductive health for this population. Being on antiretroviral therapy was not associated with fertility intention in this population. Respondents who were of young age, were single or had lost a child were unlikely to have fertility intentions.

Several studies that have described pregnancy intention rates in different contexts of people living with HIV have reported rates that range from $17 \%$ in Uganda [10] to $63 \%$ in Nigeria [17]. Studies from Zambia [18] and Zimbabwe [19] found no effect of HIV diagnosis on subsequent childbearing, implying that pregnancy intentions were unaffected by HIV diagnosis. Fertility intentions among HIV positive persons are more common in developing countries (where the overall fertility in the population is still high, contraceptive use is low, and unmet need for contraception is high). They have also been noted in more developed countries such as Brazil, United States of America, France and Italy [20-26].

The finding of lack of association of fertility intention and antiretroviral therapy contrasts that of Maier et al [13] in the same socio-cultural context who had found that antiretroviral therapy had increased fertility desires (but had little influence on pregnancy rates and live birth rates of HIV positive individuals). At the time when the HIV pandemic in the developing countries matures, the majority of affected individuals are in the reproductive age, where they may desire to have children in spite of their HIV status $[10,15,27]$. Factors influencing HIV positive people's pregnancy decisions, especially partner's desire to have a child and young age do not differ from those of influencing HIV non-infected women [28].

The study findings are consistent with previous research which showed that many cohabiting couples do not mutually know their HIV status [10,13,29]. HIV prevention programs to protect the negative partners in discordant couples in Uganda face the dilemma of nondisclosure of HIV status for HIV positive individuals $[14,16]$, many of whom are already taking antiretroviral drugs. Some of the contextual factors that influence sexuality, fertility intentions, reproductive decision making and subsequent sexual behavior of HIV positive individuals are personal and partners' desire to have children, societal reproductive expectations and non-disclosure of HIV sero-status in sexual relationships $[14,16,29]$. These contextual factors, which seem not to have changed for HIV positive individuals in the era of access to antiretroviral therapy, might be partly responsible for the high unmet need for contraception [10,30,31].

\section{Conclusion}

Factors that influence fertility intention among HIV positive persons were age of the respondent, marital status and whether any of the respondents' children had died. Respondents who were of young age, were single or had lost some children were unlikely to desire a child in the near future. Being $\mathrm{n}$ antiretroviral therapy was not associated with desire to have a child in the near future. The finding that counseling and support given from an HIV care and treatment center did not alter HIV positive individuals' perceptions and subsequent sexual behavior has implication for counseling these clients.

\section{Acknowledgements}

The authors are grateful to colleagues of the Kabale hospital and HIV treatment centre; to research assistants Linda Owembabazi, Ndyanabawe Idah, and Mugisha Gideon; as well as to all the research participants.

\section{Author details}

${ }^{1}$ Department of Obstetrics and Gynecology, Makerere University College of Health Sciences, P.O. Box 7072, Kampala, Uganda. ${ }^{2}$ Kabale Regional Hospital, Department of Obstetrics and Gynecology, P.O.Box 7 Kabale, Uganda. ${ }^{3}$ Department of Obstetrics and Gynecology, Makerere University Medical School, P.O. Box 7072, Kampala, Uganda.

\section{Authors' contributions}

$\mathrm{MOO}$ and OK conceptualized the study. DKK, OK and MO designed the study instrument. MOO collected the data. DKK and OK conducted the data analysis. DKK wrote the first draft of the manuscript. All co-authors contributed to revision of the subsequent draft manuscripts and approved the final and this version of the manuscript.

\section{Competing interests}

The authors declare that they have no competing interests.

Received: 7 July 2010 Accepted: 11 October 2010

Published: 11 October 2010

\section{References}

1. Newell ML: Vertical transmission of HIV-1 infection. Transactions of the Royal Society of Tropical Medicine and Hygiene 2000, 94:1-2.

2. Nebié $Y$, Meda N, Leroy V, Mandelbrot L, Yaro S, Sombié I, Cartoux M, Tiendrébeogo S, Dao B, Ouangré A, Nacro B, Fao P, Ky-Zerbo O, Van de Perre $P$, Dabis F: Sexual and reproductive life of women informed of their HIV seropositivity: a prospective cohort study in Burkina Faso. Journal of the Acquired Immune Deficiency Syndrome 2001, 28(4):367-72.

3. Kline A, Strickler J, Kempf J: Factors associated with pregnancy and pregnancy resolution in HIV seropositive women. Social Science and Medicine 1995, 40:1539-1547.

4. Stephenson MJ, Griffioen A: The effect of HIV diagnosis on reproductive experience. Acquired Immune Deficiency Syndrome 1996, 10:1683-1687.

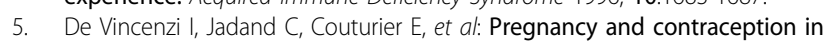
a French cohort of HIV-infected women. Acquired Immune Deficiency Syndrome 1997, 11:333-338.

6. Thackway SV, Furner V, Mijch A, et al: Fertility and reproductive choice in women with HIV-1 infection. Acquired Immune Deficiency Syndrome 1997, 11:663-667.

7. Bedimo AL, Bessinger R, Kissinger P: Reproductive choices among HIVpositive women. Social Science and Medicine 1998, 46:171-179.

8. Allen S, Serufilira A, Gruber V, et al: Pregnancy and contraception use among urban Rwandan women after HIV testing and counseling. American Journal of Public Health 1993, 83:705-10.

9. Heyward W, Batter V, Malulu M, et al: Impact of HIV counseling and testing among child-bearing women in Kinshasa, Zaire. Acquired Immune Deficiency Syndrome 1993, 7:1633-137.

10. Nakayiwa S, Abang B, Packel L, Lifshay J, Purcell DW, King R, Ezati E, Mermin J, Coutinho A, Bunnell R: Desire for children and pregnancy risk behavior among HIV-infected men and women in Uganda. AIDS and Behavior 2006, 10:S95-S104. 
11. Simbayi LC, Kalichman SC, Strebel A, Cloete A, Henda N, Mqeketo A: Disclosure of HIV status to sex partners and sexual risk behaviors among HIV-positive men and women, Cape Town, South Africa. Sexually Transmitted Infections 2007, 83:29-34.

12. Ngubane N, Patel D, Newell ML, Coovadia HM, Rollins N, Coutsoudis A, Bland RM: Messages about dual contraception in areas of high HIV prevalence are not heeded. South African Medical Journal 2008, 98(3):209-12.

13. Maier M, Andia I, Emenyonu N, Guzman D, Kaida A, Pepper L, Hogg R, Bangsberg DR: Antiretroviral therapy is associated with increased fertility desire, but not pregnancy or live birth, among HIV positive women in an early HIV treatment program in rural Uganda. AIDS and Behavior 2009, 13(1):28-37.

14. Carpenter LM, Kamali A, Ruberantwari A, Malamba S, Whitworth JAG: Rates of HIV-1 transmission within marriage in rural Uganda in relation to the HIV sero-status of the partners. AIDS and Behavior 1999, 13:1083-1089.

15. Ministry of Health (MOH) [Uganda] and ORC Macro: Uganda HIV/AIDS Sero-behavioral Survey 2004-2005. Calverton, Maryland, USA: Ministry of Health and ORC Macro 2006.

16. Bunnell R, Nasozzi E, Marum J, Mubangizi S, Malamba B, Killon J, et al: Living with discordance: knowledge, challenges, and prevention strategies of HIV-discordant couples in Uganda. Clinical Infectious Diseases 2005, 17(8):999-1012.

17. Oladapo OT, Daniel OJ, Odusoga OL, Ayoola-Sotubo O: Fertility desires and intentions of HIV-positive patients at a suburban specialist center. Journal of the National Medical Association 2005, 97(12):1672-81.

18. Baylies C: The impact of HIV on family size preference in Zambia. Reproductive Health Matters 2000, 8:77-86.

19. Feldman R, Maposhere C: Safer sex and reproductive choice: findings from 'positive women: voices and choices' in Zimbabwe. Reproductive Health Matters 2003, 11:162-73.

20. Chen JL, Philips KA, Kanouse DE, Collings RL, Mil A: Fertility desires and intentions of HIV positive men and women. Family Planning Perspectives 2001, 33:144-152, 165.

21. Sowell RL, Murdaugh $\mathrm{CL}$, Addy CL, Moneyham L, Tavokoli A: Factors influencing intent to get pregnant in HIV-infected women living in the southern USA. AIDS Care 2002, 14(2):181-191.

22. Richter $\mathrm{DL}$, Sowell RL, Pluto DM: Factors affecting reproductive decisions of African American women living with HIV. Women Health 2002, 6:81-96.

23. Aglaêr A, Nóbrega, Fabíola A, Oliveira S, Marli T, Galvão G, Rosa S, Mota, Regina M, Barbosa, Inês, Dourado, Kendall Carl, Ligia R, Kerr-Pontes S: Desire for a child among women living with HIV/AIDS in Northeast Brazil. AIDS Patient Care and STDs 2007, 21(4):261-267.

24. Shonda M, Robin O, Delaney, Dianne T, Bautista, Julianne M, Serovich : Pregnancy Decisions Among Women with HIV. AIDS and Behavior 2007, 11:927-935.

25. Paiva V, Naila, Santos, Ivan, França-Junior, Elvira Filipe, Ayres Ricardo José, Segurado : Desire to have children: gender and reproductive rights of men and women living with HIV: a challenge to health care in Brazil. AIDS Patient Care and STDs 2007, 21(4):268-277.

26. Heard I, Rémi, Sitta, France, Lert, the VESPA Study Group: Reproductive choice in men and women living with HIV: evidence from a large representative sample of outpatients attending French hospitals (ANRSEN12-VESPA Study). AIDS and Behavior 2007, 21(suppl 1):S77-S82.

27. Gray RH, Wawer MJ, Serwadda D, Sewankambo N, Li C, Wabwire-Mangen F, Paxton L, Kiwanuka N, Kigozi G, Konde-Lule J, Quinn TC, Gaydos CA, McNairn D: Population-based study of fertility in women with HIV-1 infection in Uganda. Lancet 1998, 351(9096):98-103.

28. Olaitan A, Madge S, Johnson M: Contraceptive use, and knowledge of postcoital contraception amongst HIV-infected women: a comparison with an HIV negative population. British Journal of Family Planning 1996, 22:127-128.

29. King R, Katuntu D, Lifshay J, Packel L, Batamwita R, Nakayiwa S, Abang B, Babirye F, Lindkvist P, Johansson E, Mermin J, Bunnell R: Processes and outcomes of HIV serostatus disclosure to sexual partners among people living with HIV in Uganda. AIDS andBehavior 2008, 12(2):232-43.

30. Uganda Bureau of Statistics (UBOS) and Macro International Inc. Uganda: Demographic and Health Survey 2006. Calverton, Maryland, USA: UBOS and Macro International Inc. Kampala 2007.

31. Andia I, Kaida A, Maier M, Guzman D, Emenyonu N, Pepper L, Bangsberg DR, Hogg RS: Highly active antiretroviral therapy and increased use of contraceptives among HIV-positive women during expanding access to antiretroviral therapy in Mbarara, Uganda. American Journal of Public Health 2009, 99(2):340-7.

doi:10.1186/1742-4755-7-27

Cite this article as: Kakaire et al:: Factors that predict fertility desires for people living with HIV infection at a support and treatment centre in Kabale, Uganda. Reproductive Health 2010 7:27.

\section{Submit your next manuscript to BioMed Central and take full advantage of:}

- Convenient online submission

- Thorough peer review

- No space constraints or color figure charges

- Immediate publication on acceptance

- Inclusion in PubMed, CAS, Scopus and Google Scholar

- Research which is freely available for redistribution 